\section{legitimacy without legality? war-making with and without the UN}

\section{thomas bräuninger}

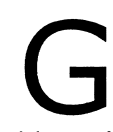

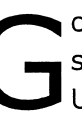
vernment officials and legal cholars broadly agree that the US-led war in Iraq had the blemish of being neither backed by a United Nations Security Council (UNSC) mandate nor by a broad multilateral coalition. As regards the offender, even legal scholars disagree, arguing either that a deadlocked UNSC failed and the US 'did indeed have all authority it needed' (Glennon, 2003), or that, in the absence of UNSC approval, US use of force amounted to 'a war of aggression' (International Commission of Jurists, 2003). Both conclusions are based on the assumption that the pursuit of power was the prime motivation for UNSC member states. In this article, I take a different stance. I consider the possibility that UNSC members were driven by the pursuit of truth, not power. In the end, the UNSC failed because viewpoints were too hastily formulated. The French government is as much to blame as the US government for disturbing the functioning of the UNSC.

\section{LEGALITY AND LEGITIMACY OF THE USE OF FORCE}

Before I discuss whether the war in Iraq was legal and 'just' or illegitimate and a violation of international law, let me briefly reconsider the accusations against Iraq (Wolfrum, 2003). First and foremost, there was a demand for compliance with UNSC Resolution 687 (1991), confirmed by Resolution 1441 (2002), demanding the destruction of weapons of mass destruction and cooperation with UN monitoring procedures. Iraq was also believed not to have met humanitarian obligations under international treaties, notably the return and repatriation of prisoners of war and civilians. Finally, Iraq was considered to support international terrorism and to violate fundamental human rights. None of these violations, however, were likely to result in a UNSC mandate for the use of force. While the possession of weapons of mass destruction would have constituted a severe threat to international peace, especially in combination with the alleged link to international terrorism, the evidence for these allegations was anything but clear.

The follow-up question is who was entitled to use force in order to compel Iraqi compliance. Under the UN Charter the use of force is permitted only in cases of self-defence or under UNSC mandate. While the issue is disputed among legal scholars, the general view is, first, that the US right to self-defence required a concrete attack or at least an attack that was immediately imminent. The US conception of 'pre-emptive self-defence', however, appeared to abandon any objective certification of the imminence of an attack (Wolfrum, 2003: 5). Second, a prominent perception of international 
law is that resolution 1441 does not contain an explicit UNSC authorisation for the use of force, even though states have often used force despite the absence of its mention in the relevant UN resolutions (Lobel and Ratner, 1999). Finally, whilst a large body of legal and political science literature attempts to justify a unilateral right to humanitarian intervention, all arguments in favour must be seen to have recourse to standards outside positive international law; neither the UN Charter nor state practice provides for such a right (Murphy, 1996).

I acknowledge that I have abbreviated this complex debate to a probably unjustifiable extent. I argue, however, that the US government was keen to get the full backing, or at least the support, of a majority of non-permanent UNSC members because it considered its own action as possibly illegal. In fact, through its painstaking efforts to gain public support, despite the unshakable French refusal, the US clearly sought to gain legitimacy for a military operation that was considered illegal by established standards of international law. Likewise, Danish and Polish cooperation was intended to increase the legitimacy of a unilateral operation rather than provide substantial military assistance.

While these points are hardly new one crucial aspect has often been overlooked in the debate so far. What 'delegitimised' UNSC authority from the US perspective? Why did the US government seek UNSC approval and ye consider its own decision as legitimate when the UNSC failed to adopt a resolution supporting such decision? In what follows, I argue that the US did not deprive the UNSC of the authority to approve the use of force per se but considered the way the UNSC actually handled the Iraq crisis as inappropriate and distorted and, consequently, the (non-)decision on the use of force as not binding. My argument is that the Iraqi case was an essentially judicial question but that the refusal of some UNSC members to consider a new resolution undermined the procedure as a whole - probably more so than US insistence on UNSC approval.

\section{VOTING AS A MECHANISM FOR TAKING JUDICIAL} DECISIONS

It is often argued that the UNSC is a political body that makes inherently political decisions. This implies that the decisions taken are inherently normative. I disagree with this position. To clarify, it is the case that the UNSC often or even most often has to deal with issues that are inherently normative. The decision in favour of a new 'oil-for-food' programme in April 1995, for instance, was a politica one. There was no disagreement about the facts but different ethical standpoints. The Iraqi case was differ ent. If the Iraqi government was not compliant with Resolutions 687 and 1441 or if it had supported international terrorist groups, then it was clearly in breach of international law. The crucial question then was whether Iraq was guilty of what it was accused. This, however, is more judicial than a political question and should be analysed as such.

Social choice theory offers a simple method of studying judicial decision-making. Starting with the. wellknown work of Condorcet, a vast literature has studied the capacity of groups to make best decisions when actors have a common objective function, i.e. they prefer the statement ' $A$ is true' whenever the state of the world is A but ' $B$ is true' if $B$. The realworld problem stems from the fact that actors have beliefs but are inherently uncertain about the true state of the world. Thus, the uncertainty of assessments rather than a divergence of preferences make a collective decision necessary. But the question of how to arrive at the best decision is far from trivial. The key finding of Condorcet was that even under weak assumptions groups acting under simple majority rule make better decisions than individuals.

The Iraqi case differs, however, in one critical respect from the information aggregation problem described above. The question at stake was whether the Iraqi government had or had not breached resolutions 687 and 1441. Thus, the two alternative states of the world were not identical but a verdict of 'guilty' or 'not guilty' had to be produced. Convicting an Iraqi government that had breached international law and acquitting an innocent one was arguably equally desirable for all UNSC members. Convicting and starting war on an innocent Iraq was most likely less acceptable than acquitting a guilty one. In that respect the Iraqi case in the UNSC was indeed less an information aggregation problem than a trial. The fact that innocents should not be convicted under any circumstances is exactly the reason why unanimity is generally preferred to majority rule when it comes to decision-making in criminal trials. The conventional wisdom is that use of the unanimity rule minimises the chances of convicting an innocent defendant.

The obvious problem at this point is how to weigh the odds of starting war on an innocent Iraq against the risk of acquitting an Iraqi government that is in possession of weapons of mass destruction and willing to make use of
'The crucial question then

was whether Iraq was

guilty of what it was

accused. This, however,

is more a judicial than

a political question

and should be analysed

as such.'

them. UNSC members had different views on this as well as different standards of reasonable doubt. Considering the rhetoric of the main antagonists, it is fair to assume that the US government was willing to take the considerable risk of a wrongful conviction whilst the French government claimed to have comparatively high standards when asking for 'more evidence' to justify a conviction. To study the implications of such a situation, let me first introduce some notation.

Suppose that there are $n$ jurors $i=1, \ldots, n$ who decide the fate of a guilty $(G)$ or innocent $(I)$ defendant by either convicting $(C)$ or acquitting $(A)$ her. Any juror is uncertain about the defendant's guilt but receives one of two signals, innocent ( $i)$ or guilty $(g)$, in the form of private or public information. I assume that the probability of receiving a correct innocent signal is equal to the probability of receiving a correct guilty signal ${ }^{2}$

$$
P(i \mid I)=P(g \mid G)=p
$$

and that the signal is indeed informative, or $p \in(1 / 2,1)$. Any juror bases her vote either to convict or to acquit on this signal. All jurors are assumed to 
have similar preferences given by $u_{i}(A \mid I)=u_{i}(C \mid G)=0, u_{i}(A \mid G)=q_{i}-1$ and $u_{i}(C \mid I)=-q_{i}$ where $q_{i} \in[0,1]$. The parameter $q_{i}$ represents the threshold of reasonable doubt and any juror receiving the signal 'guilty' votes sincerely for conviction if and only if $p>q_{i}$. Now, let $k$ define the voting rule. Under unanimity $(k=n)$, all jurors have to vote for conviction for the defendant to be convicted. Accordingly, a guilty verdict under simple majority rule requires a conviction vote of $k=(n+1) / 2$ jury members (if $n$ is odd). Why the unanimity rule is preferable can be seen when we look at the odds that incorrect verdicts are reached under various rules. In general, under a k-majority rule, the probability that an innocent defendant is convicted is

$$
P n, k(C \mid I)=\sum_{j=k}^{n}\left(\begin{array}{l}
n \\
j
\end{array}\right)(I-p)^{j P n-j}
$$

and the probability that a guilty defendant is acquitted is

$$
P n, k(A \mid G)=1-\sum_{j=k}^{n}\left(\begin{array}{l}
n \\
j
\end{array}\right) P j(I-p)^{n-j}
$$

This implies that $P(C \mid I)$ is lower under unanimity than any other $k$-majority rule. The obvious caveat at this point is that guilty defendants are likely to be acquitted under unanimity but less often under majority rule. What can be learned from this?

\section{A SIMPLE MODEL OF THE IRAQ TRIAL}

To simplify matters I consider the UNSC as consisting of the five permanent members, only. This does not damage my argument since I want to see the effect of the veto provision in the UNSC and compare the results to a situation where verdicts on the breach of resolutions are reached according to the majority rule. I also consider the situation where responsibility for the decision as to guilt or innocence lies with a single UNSC member, as the superpower. This was the actual outcome: despite the fact that the UNSC did not sentence the Iraqi government, the US government stuck to its own conviction and started war.

Table 1 shows error probabilities for various scenarios and voting rules. In the baseline scenario all UNSC members strictly prefer correct to incorrect verdicts. Assuming that all permanent members have some expertise based on UN inspectors' reports or intelligence, and receive a signal the probability of whose correctness $p=.8$, the likelihood that an innocent Iraqi government is unanimously convicted is indeed low, namely $P(C \mid I)=.0003$. This comes at a cost of a high probability of acquitting a guilty raqi government, $P(A \mid C)=.6723$. Under simple majority rule both incorrect verdicts are equally likely entailing a, perhaps unacceptably high, risk of waging an unjustified war. In any case, a superpower acting unilaterally is more likely to make either mistake than a 5-member UNSC acting under majority rule.

Admittedly, this is not a terribly realistic scenario. Rather, the US government seemed to be convinced that Iraq was in breach of UN resolutions.

I am arguing neither that the US was acting strategically nor that it tried to mislead other UNSC members. ${ }^{3}$ My argument is that the US had an extremely low threshold of reasonable doubt. For the sake of parsimony, assume that the threshold is $q=0$ so that avoiding the acquittal of a guilty Iraq is the only goal. As a result, the superpower ignores the signal and convicts always. ${ }^{4}$ Conversely, right

Table 1: Error probabilities in a 5-member UNSC and of superpower acting unilaterally

\begin{tabular}{l|c|c|c|c|c|} 
Voting rule & & $k=5$ & $k=4$ & $k=3$ & superpower \\
\hline Baseline & $P(C \mid I)$ & .0003 & .0067 & .0579 & .2000 \\
& $P(A \mid G)$ & .6723 & .2627 & .0579 & .2000 \\
& & & & & \\
Superpower always & $P_{C}(C \mid I)$ & .0016 & .0272 & .1808 & 1 \\
convicts $\left(q_{j}=0\right)$ & $P_{C}(A \mid G)$ & .5904 & .1808 & .0272 & 0 \\
Challenger always & $P_{A}(C \mid I)$ & 0 & .0016 & .0272 & .2000 \\
$\begin{array}{l}\text { acquits (qj=1) } \\
\text { Superpower always }\end{array}$ & $P_{A}(A \mid G)$ & 1 & .5904 & .1808 & .2000 \\
$\begin{array}{l}\text { convicts, challenger } \\
\text { always acquits }\left(q_{i}=0,\right.\end{array}$ & $P_{A C}(C \mid I)$ & 0 & .0080 & .1040 & 1 \\
$\left.q_{j}=1\right)$ & & & .4880 & .1040 & 0
\end{tabular}

Note: I assume that $p=.8$ and, unless otherwise stated, $q_{i}<p$.

from the beginning, France expressed its intention not to support a new resolution, let alone US unilateral action. I assume that $q=1$, that is, France wants to avoid all risk of convicting an innocent defendant and thus always acquits whatever its signal is. I consider these scenarios one by one.

If the superpower always convicts, the probability of acquitting a guilty defendant decreases to .5904 under the UNSC veto system but this comes at the expense of a higher probability of convicting one who is innocent. Majority rule is no feasible alternative; it even reverses the odds ratio of the two erroneous decisions. From a judicial perspective, a 'superpower ruling' is the worst option. Thinking of France as the superpower's challenger who always acquits, results in the opposite. There is no chance of a conviction under the veto rule but the chances of convicting an innocent defendant are turned around under simple majority rule. Finally, if both the superpower and the challenger have extreme thresholds, the chances of conviction are again nil under unanimity, and even under simple majority rule the likelihood that one of the two errors occurs is significant. In sum, while the US government's expressed willingness to push for the authorisation of use of force against Iraq obviously biased the UNSC decision, the French made the procedure pointless.

\section{CONCLUSIONS}

Is there anything we can learn from a social choice approach to the most recent UNSC crisis? Condemning the French government would be jumping to conclusions as it is doubtful whether the Iraqi case before the UNSC is adequately represented by the ideal jury situation analysed above. Usually, when the UNSC has to determine whether or not a breach of or threat to international peace exists, members have to decide on both matters of fact and standards. A more tentative conclusion is that the Iraqi case had elements of both so 
that clinging desperately to a purely realist perspective and interpreting the US war on Iraq as the illegal military action of a hegemon trying to abuse an international institution to back a predetermined unilatera action, would be only half the story. In fact, the behaviour of both governments is explicable in terms of different standards of reasonable doubt. For sure, nothing supports the view that the US was indeed more capable than the UNSC of making a correct guilty verdict. But it was French reluctance that distorted UNSC decisionmaking and thereby the institution's 'legitimacy by procedure'. It was this attitude that ultimately de-legitimise the institution that was deemed to be the proper authority for approving the use of force.

\section{Notes}

1 This and the following results are based on the assumption that jurors vote sincerely, i.e. they vote for a guilty verdict whenever the private and public information available to them indicates guilty and vice versa. Such behaviour, however, is in general inconsistent with Nash equilibrium behaviour (Austen-Smith and Banks, 1996)

2 I also assume that $P(I)=P(G)=1 / 2$. Both assumptions simplify notation but the general conclusions drawn hold even if the states are not equally likely.

3 Nor am I denying that this happened.

4 There must be reasons why the US Government was so tough but this is not my point here. I take this as a (reasonable) assumption.

5 If one actor always convicts, $P C^{n, k}(\cdot \mid \cdot)=P^{n-1, k-1}(\cdot \mid \cdot)$

If one actor always acquits,

$P_{A^{n, k}}(\cdot \mid \cdot)=P n-1, k(\cdot \mid \cdot)$

one acquits,

$P_{A C^{n, k}(\cdot \mid \cdot)=P n-2, k-1}(\cdot \mid \cdot)$

\section{References}

Austen-Smith, D. and J. Banks (1996) 'Information Aggregation, Rationality, and the Condorcet Jury Theorem', American Political Science Review, 90:1, 34-45.

Glennon, M. (2003), 'Why the Security Councl Failed', Foreign Affairs, 82:3, 16-35.

International Commission of Jurists (2003) Iraq - ICJ deplores moves toward a war of ggression on Iraq, Press Release, 18 March.

Lobel, J. and M. Ratner (1999), 'Bypassing the Security Council', American Journal of International Law, 93:1, 124-154.

Murphy, S. (1996), Humanitarian Intervention, Philadelphia, University of Pennsylvania Press.

Wolfrum, R. (2003), Iraq - A crisis for our system of collective security, unpublished manuscript, Heidelberg, Max Planck Institute for Comparative and International Law. 